All this makes for such fascinating reading that I would have preferred more of the highly readable text and fewer illustrations - even though many of the latter are delightful, particularly the polished sketches by Baines and the early photographs. My one serious complaint concerns the maps. It is ironic that, in this of all books, these are heavily drawn, inadequate and, in at least one case (the Musandam map on p.224), inaccurate. Furthermore the two contemporary maps included are almost illegible, they lack captions and it was only on reading the acknowledgements that I learnt of their source and date.

This book cannot be a comprehensive history of the RGS, and Mr Cameron has wisely concentrated on the expeditions to areas that have long been the favourites of armchair travellers - the Arctic and Antarctic, the Himalayas and Africa. New to me were most of the early explorers of Australia and the brave Pundits who secretly and at great hazard to themselves surveyed on foot almost the whole of the Eastern Himalayas in the 1850 s to 1870 s. Childhood heroes - Burton, Speke, Livingstone, Stanley, Nansen, Shackleton, Scott, Hunt, Hillary and Tenzing (but only one heroine, Florence Baker) are included. $\mathrm{Mr}$ Cameron also gives credit to many other explorers, less well known but equally deserving of fame, who doggedly helped fill in the blanks on the maps. I am only sorry that room could not be found in this catalogue of illustrious names for some

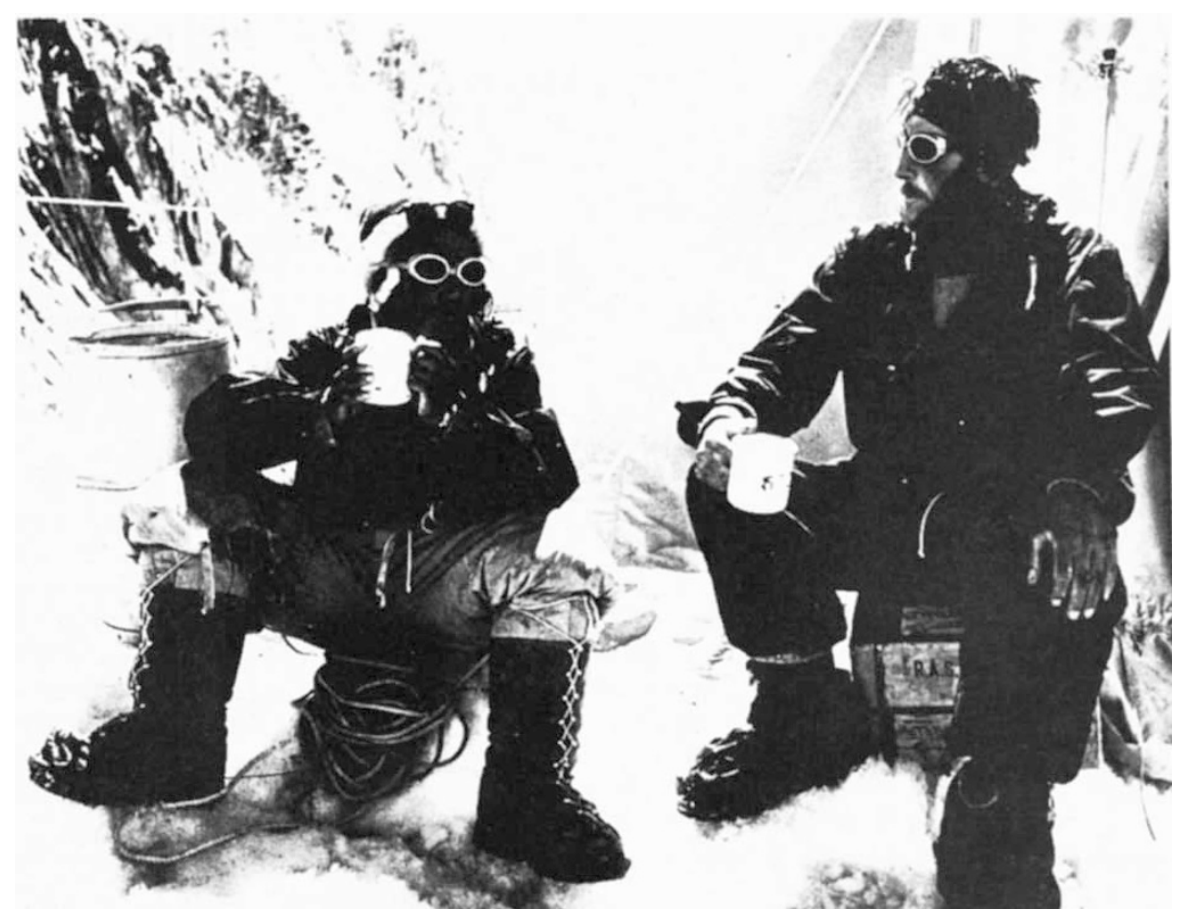

After the summit of achievement: Hillary and Tenzing after the first ascent of Everest, May 1953.

mention of the Arabian travels of Wilfred Thesiger and Freya Stark.

$\mathrm{Mr}$ Cameron brings readers up to date with accounts of some of the recent, increasingly scientific, expeditions that the RGS has supported - to the Mato Grosso (1967-1969), the Musandam Peninsula (1971) and the Mulu rain forest in Sarawak
(1977-1978), for example. The book ends with a chapter on the role of the Society today as it continues to advance geographical knowledge. It is a quieter role, without the glamour and heroics of the past, but noless important for that. $\square$

Sarah Bunney is a freelance writer and editor.

\title{
Stonehenge and its times: a layman's and a scholar's view
}

\section{R.J.C. Atkinson}

The Enigma of Stonehenge. By John Fowles and Barry Brukoff. Pp.128. (Cape/ Summit: 1980.) £6.95, \$19.95. The Age of Stonehenge. By Colin Burgess. Pp.402. (Dent/Biblio: 1980.) £12, \$25.

THESE are two very different books, which have in common only the name of Stonehenge in their titles. The first is the result of a most happy collaboration between an English novelist and an American photographer, both of genius, to give a unique picture of Stonehenge itself. The second is a sober and most scholarly interpretation (John Fowles would call it clinical) of the prehistory of the British Isles during the floruit of Stonehenge.

Fowles's short account begins with his own first happy visit to Stonehenge as a child, and with his last, less happy because the stones are now closed to the public. His summaries of the archaeological background and of the sequence of building can be faulted in detail by the pedantic specialist; but they are based on a wide and critical reading, and they are written with a delusive ease and with an informed humanity which puts to shame the earnest but pedestrian locutions of most other recent writers about Stonehenge, myself included.

He asks: "What is Stonehenge for?". For me this is an unanswerable question, because I do not think that the mute material evidence of prehistory can tell us, except in a quite trivial sense, what people thought in the remote past, but only, up to a point, what they did. This is not to say, as Fowles hints, "a pox on all speculation"; but speculation and valid inference are two very different things, and must be distinguished, perhaps better than Fowles does.

In his longest chapter, "The MoonMirror', he perhaps accepts too easily some of the astronomical uses ascribed to Stonehenge by Hawkins, Hoyle, Newham and Thom. Moreover, he confuses the Metonic Cycle with the period of rotation of the lunar nodes, and falsely explains the position of the Heel Stone, as a possible marker for the mid-point of the azimuthal limits of most northerly moonrise, in terms of the latitude of Stonehenge. $\mathrm{He}$ also infers, quite incorrectly, that the absence of any discussion of astronomical theories from my own book Stonehenge (Hamish
Hamilton, 1956) was intended as a "monumental snub" to Hawkins, Hoyle and Thom. Far from it. My book was written in 1955, before any of these theories were published, and has since been reprinted only with appendices to bring the results of later excavation up to date.

Fowles's luminous text ends with an historical and personal appreciation of Stonehenge-in-the-mind, and not least in the mind of that eerie and disturbing seer, William Blake. He protests throughout against "a quite unnecessary polarity in twentieth-century society between pure science and impure speculation". This echoes what I wrote in Nature $\mathbf{2 6 5}, 11$; 1977). The science is far from pure, because much of the basic data are at best uncertain, and at worst corrupt. The speculation is likewise not impure, merely because it is speculation; but it is not inference compelled by the evidence of Stonehenge-on-the-ground.

Barry Brukoff's photographs, unnumbered and uncaptioned, match John Fowles's text in their sensitivity and imagination. No one has better frozen in print an image of Stonehenge. His 


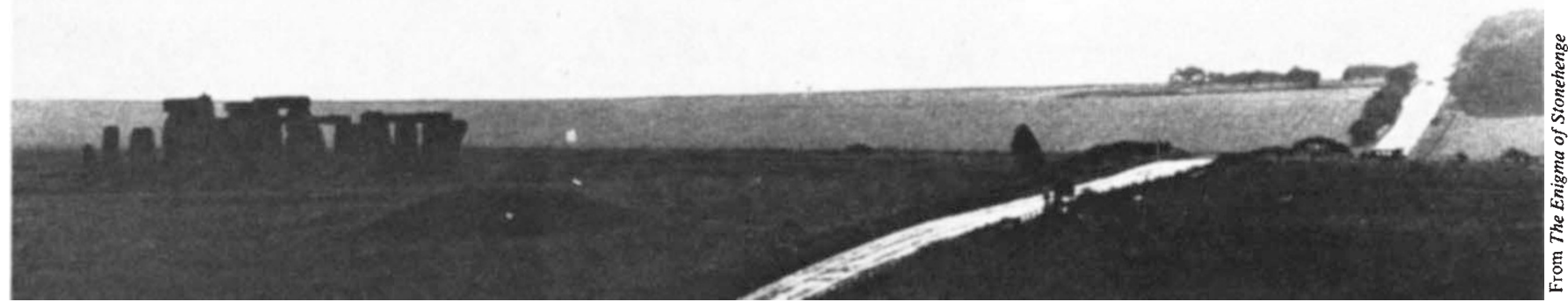

occasional use of a wide-angle lens gives a sense of spaciousness which the monument itself belies, though one which echoes some of William Stukeley's engravings of 1740 . Occasionally a Sun or Moon has been added by photomontage for dramatic emphasis at far more than natural size. Not the least haunting of these photographs capture, as none has before, the texture of the surface of some of the sarsen stones, in which each beholder will see his own private vision.

This book, in words and images, will enlarge the consciousness of every visitor to Stonehenge, past and future.

Colin Burgess's book will likewise extend the thinking of every British prehistorian, and of colleagues abroad. It is a major advance in the synthesis of the new evidence which has become available, almost explosively, from excavations and the analysis of museum collections during the past 20 years for the period of 3,000 years from 3,200 BC, which corresponds roughly to the use of Stonehenge.

He divides this into five periods, each identified by a type-site, and each characterized in his view by specific practices or trends, in ritual architecture for worship or burial, and in the design and manufacture of artefacts. This is a convenient chronological device for avoiding the constraints of ill-fitting radiocarbon dates with their present state of uncertainty. He gives also, however, a list of 215 radiocarbon dates in their raw (uncorrected) form. One may ask whether these, when corrected, may not provide a better framework than a series of largely arbitrary periods which, because they are new, may be adopted and maintained long after they have ceased to be significant. $\mathrm{He}$ rejects, rightly, the old and now outmoded divisions of the conventional Neolithic and Bronze Age.

Burgess's main thesis is that tribal territories had already been fixed by the end of the fourth millennium $\mathrm{BC}$, and that thereafter cultural change took place by the adoption of innovations across persisting tribal boundaries, with local adaptations increasing in proportion to the distance from the primary source. This is a possible model, though the one which rests on a number of quite unverifiable assumptions, and one which rejects explicitly the "invasion hypothesis" that has long been dominant in explanations of British prehistory.

In his proper desire to emphasize cultural continuity, however, he has perhaps underestimated the impact of the Beaker people coming from across the North Sea and the Channel in the middle of the third millennium $\mathrm{BC}$. Whether this was an invasion, an incursion or an immigration, or a series of any of these processes, on whatever scale, is largely a semantic question. What is evident is that there was a fairly rapid innovation in material culture, superimposed on native practices which survived by absorption. This cannot be explained except by an incoming from abroad, and a break in the continuity of native traditions. Burgess does admit, quite rightly, that at the end of the "Age of Stonehenge" there may have been an influx of foreigners who established the succeeding "Age of Hill

Forts', though they are far less well represented in the archaeological record than the Beaker people.

This is a book for specialists in British prehistory, and not least for university students. It is well illustrated by photographs of sites and objects. The numerous line-drawings of plans and artefacts have been rather over-inked and thus harshly reproduced, and the inclusion of north-points and scales is a little capricious. Minor defects apart, it is a major contribution to the understanding of a formative period of our prehistoric past.

R.J.C. Atkinson is Professor of Archaeology at University College, Cardiff.

\section{The rediscovery of ancient Ebla}

\section{J.M. Munn-Rankin}

EBLA: An Empire Rediscovered. By Paolo Matthiae. Translated by C. Holme. Pp.237. (Hodder and Stoughton/ Doubleday: 1980.) £12.95, $\$ 14.95$.

THE excavation in 1974 and 1975, at the north Syrian site of Tell Mardikh, ancient Ebla, of a mid-third millennium palace with some 20,000 cuneiform tablets written in a previously unknown Semitic language was an event of outstanding importance for historians of early urban society in the Near East.

Prior to this discovery, archaeological and textual evidence for developments in Syria during the Early Bronze Age (c. 2900-2000 BC) was meagre. As compared with the earliest centres of civilization, Sumer and Egypt, relatively few Syrian excavations had penetrated below second millennium levels and of these most were stratigraphic sondages. At only a few major sites, mainly in the north-east, had more extensive excavation produced significant evidence of urban settlement. Literacy was attested only at Mari on the Euphrates where a Semitic language was written in the cuneiform script of Sumer. Of the population it could be said only that it was probably of mixed ethnic origin and that its social structure ranged from primitive nomadism to complex urbanism. It was, however, apparent that the urban civilization of Sumer, in existence by the second half of the fourth millennium, had played a major role in the formation and subsequent development of Syrian civilization, the main impetus for the expansion of its influence being the need for the timber, stone and metal in which southern Iraq is deficient. As regards the political geography of Syria, a limited amount of information was provided by the records of Sumer, among the earliest being the campaign reports of Sargon and Naram-Sin of Agade (c. 24th and 23rd centuries $\mathrm{BC}$ ) which list cities conquered on expeditions to the Mediterranean. Among them is Ebla.

This inadequate picture of the early culture and history of Syria is now being transformed by the excavations of Paolo Matthiae of Rome University at Tell Mardikh. In this report on their progress, he describes and assesses the significance of the finds made between 1964 and 1976. The site was occupied from the latter half of the fourth millennium until the sixteenth century $\mathrm{BC}$, but work has so far been concentrated on the cities of the mid-third and early second millennia. Excavation of the latter has made a major contribution to knowledge of the architecture and art of that period, but of far greater importance are the unique discoveries in the earlier level.

Here was a major urban centre with central acropolis and lower town, perhaps covering some 56 ha, encircled by a defensive wall. Excavation has exposed part of an acropolis palace, including an 